\title{
Headache, Delirium or Encephalitis? A Case of Residual Mutism Secondary to Anti-NMDA Receptor Encephalitis
}

\author{
Omar Jiménez-Zarazúa ${ }^{a, b} \quad$ María Andrea Martínez-Rivera ${ }^{a, b}$ \\ Pedro Luis González-Carrilloc ${ }^{c}$ Lourdes N. Vélez-Ramírez ${ }^{\mathrm{b}}$ d \\ María Alcocer-León ${ }^{\text {b, e }}$ Sandra X.L. Tafoya-Rojas ${ }^{f}$ Angélica M. \\ Becerra-Baez ${ }^{b} \quad$ Mariana A. Bravo-Martínez ${ }^{g} \quad$ Jaime D. Mondragón $^{\text {h, i }}$ \\ aDepartment of Internal Medicine, Hospital General León, León, Mexico; bepartment of \\ Medicine and Nutrition, Universidad de Guanajuato, León, Mexico; 'Department of Critical \\ Care and Neurocritical Care, Hospital General León, León, Mexico; dDepartment of \\ Radiology, Hospital General León, León, Mexico; eDepartment of Internal Medicine,

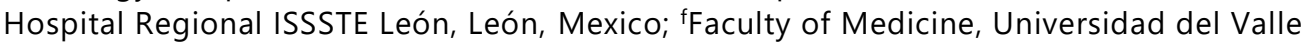 \\ de México, León, Mexico; 9Faculty of Medicine, Universidad Latina de México, \\ Celaya, Mexico; hepartment of Neurology, University Medical Center Groningen, \\ University of Groningen, Groningen, The Netherlands; 'Alzheimer Research Center \\ Groningen, University Medical Center Groningen, University of Groningen, Groningen, \\ The Netherlands
}

\section{Keywords}

Anti-N-methyl-D-aspartate receptor encephalitis · Delirium $\cdot$ Headache disorders $\cdot$ Mutism

\begin{abstract}
Encephalitis is a heterogeneous syndrome that is diagnosed through clinical assessment and the assistance of laboratory, neuroimaging and electroencephalographic workup. Over the past 10 years, autoimmune encephalitis has been more frequently recognized; however, most reports come from highly specialized hospital settings. Anti-N-methyl-D-aspartate receptor 


\section{Case Reports in Neurology}

Case Rep Neurol 2019;11:330-343

DOI: $10.1159 / 000504016$

2019 The Author(s). Published by S. Karger AG, Basel www.karger.com/crn

Jiménez-Zarazúa et al.: Headache, Delirium or Encephalitis

(NDMAR) encephalitis has been associated with paraneoplastic encephalitis syndromes and was first recognized in 2005. We present the case of a 34-year-old male patient who debuted clinically with a headache associated with neuropsychiatric symptoms (i.e., visual and auditory hallucinations, anxiety, aggressiveness) and memory deficits, progressing to autonomic dysfunction (i.e., tachycardia and hypertension), seizures, and stupor with catatonic features. Initially, infectious, metabolic, and toxicological etiologies were excluded; followed by the assessment of immunological and paraneoplastic etiologies, yielding positive IgG levels for antiNMDAR antibodies. The patient was treated successfully with systemic steroid therapy and therapeutic plasmapheresis, while mutism was the only sequela. Although large case series reporting on paraneoplastic and autoimmune anti-NMDAR encephalitis have been reported in the literature in recent years, this case is of particular importance due to the stepwise differential diagnosis and treatment management procedure that was used in a regional but not highly specialized hospital setting.

(C) 2019 The Author(s)

Published by S. Karger AG, Basel

\section{Background}

Encephalitis refers to the inflammatory process of the cerebral parenchyma which can produce neurological deficits $[1,2]$. Encephalitis is a heterogeneous syndrome that is diagnosed through clinical assessment and the assistance of laboratory, neuroimaging and electroencephalographic workup [2]. Etiologically, encephalitis can be divided into infectious and noninfectious (e.g., autoimmune, paraneoplastic) origins [2-4]. Over the past 10 years, recognition of autoimmune encephalitis has been more frequent as a cause of noninfectious encephalitis. Autoimmune encephalitis affects more often young adults and children [5]. Autoimmune encephalitis is associated with antibodies against neuronal antigens such as brain surface proteins, ion channels and protein receptors [3, 5-7]. Examples of autoimmune encephalitis were mediated by protein receptor antibodies against $\mathrm{N}$-methyl-D-aspartate receptor (anti-NMDAR) encephalitis, anti-gamma-aminobutyric acid (anti-GABA) receptor encephalitis, and encephalopathy with antibodies against glial fibrillary acidic protein, among many others $[3,5,6]$. Autoimmune encephalitis must fulfill three criteria: (1) subacute onset of clinical signs (i.e., rapid progression in less than 3 months) and symptoms (e.g., memory loss, altered mental state, movement disorders, and neuropsychiatric symptoms); (2) onset of focal neurologic deficits or seizures that are not explained by a previous medical condition; and (3) exhaustive altered state of consciousness diagnosis for other common etiological causes (e.g., infectious, metabolic, paraneoplastic, and toxicological) must be performed [3].

Anti-NDMAR encephalitis has been associated with paraneoplastic encephalitis syndromes, first recognized in a series of case studies in 2005 [8]. In a single-site retrospective study of patients with a previous diagnosis of encephalitis of unknown origin, 7 out of 505 cases fulfilled criteria for suspicion of autoimmune encephalitis: (1) encephalitic signs with psychiatric symptoms such as agitation, paranoid thoughts, irritability, or hallucinations; (2) seizures; (3) cerebrospinal fluid (CSF) inflammation; and (4) exclusion of viral or bacterial infection and 6 of the analyzed CSF samples were positive for anti-NMDAR antibodies [9]. Furthermore, anti-NMDAR encephalitis has previously been reported to be more prevalent than viral encephalitis [10]. Immunoglobulin G (IgG) NMDAR antibodies are highly specific for anti- 


\section{Case Reports in Neurology}

Case Rep Neurol 2019;11:330-343

DOI: $10.1159 / 000504016$

2019 The Author(s). Published by S. Karger AG, Basel www.karger.com/crn

Jiménez-Zarazúa et al.: Headache, Delirium or Encephalitis

NMDAR encephalitis [11]. However, although serum anti-NMDA levels can be detected in patients with NMDAR encephalitis, the sensitivity of NMDAR antibody testing is higher in CSF than in serum, reaching a sensitivity of $100.0 \%$ [95\% CI, 98.5-100] compared to $85.6 \%$ [95\% CI, 80.7-89.4] [12]. Clinically, anti-NMDAR encephalitis is associated with fever, headache, and general malaise resembling a virial infection. After this prodromal stage, patients develop psychiatric symptoms [13], as well as focal neurological deficits, memory deficits, and movement disorders [14].

We present the case of a patient with autoimmune encephalitis secondary to anti-NMDAR. The patient debuted clinically with a headache associated with neuropsychiatric symptoms (i.e., visual and auditory hallucinations, anxiety, aggressiveness) and memory deficits, progressing to autonomic dysfunction (i.e., tachycardia and hypertension), seizures, and stupor with catatonic features. Although large case series reporting on paraneoplastic and autoimmune anti-NMDAR encephalitis have been reported in the literature in recent years, this case is of particular importance due to the stepwise differential diagnosis and treatment management procedure that was used in a regional but not highly specialized hospital setting. This diagnostic management procedure involved initially excluding infectious, metabolic, and toxicological etiologies, followed by the assessment of immunological and paraneoplastic etiologies, yielding positive IgG levels for anti-NMDAR antibodies. The patient was treated successfully with systemic steroid therapy and therapeutic plasmapheresis; moreover, mutism was the only sequela.

\section{Clinical Presentation}

A 34-year-old male presented to the Emergency Department complaining of a headache characterized by tightness in the frontoparietal regions that had progressively increased in intensity from $4 / 10$ on the visual analog scale for pain to $7 / 10$ at the time of admission. The headache initially remitted with the use of nonsteroidal anti-inflammatory drugs. The patient developed neuropsychiatric symptoms after a week of the headache onset, which included anxiety, aggressiveness, and visual, as well as auditory hallucinations. A couple of days before the patient was admitted to the hospital, he developed anterograde memory deficits. The patient did not report any symptoms related to an acute infectious process (e.g., fever or malaise), nor alterations in his sleep-wake cycle, movement disorder or seizures. The patient's family history only included two brothers with hypertension and no other relevant aspects of family history. The patient denied the use of controlled substances; he further denied allergies, past blood transfusions, traveling to regions with endemic diseases within the last 3 months, tattoos, and body piercings.

Upon initial physical exploration, we found a recumbent patient with freely chosen body position, a Glasgow coma score of 12 (i.e., eye-opening 4, verbal response 2, motor response 6), without focal neurologic deficits, aware of his environment but with mutism, and without making eye contact. The patient's alert status fluctuated during the day between hypoactivity and somnolence, while at night psychomotor agitation predominated. Tests for meningeal irritation were positive. Pupils were isochoric and with a normal corneal reflex. The patient's integumentary system was hydrated and without alterations. Fundus examination revealed no alterations (e.g., papilledema or hypertensive changes of the retina). The musculoskeletal 


\section{Case Reports in Neurology}

Case Rep Neurol 2019;11:330-343

DOI: $10.1159 / 000504016$

(C) 2019 The Author(s). Published by S. Karger AG, Basel www.karger.com/crn

Jiménez-Zarazúa et al.: Headache, Delirium or Encephalitis

exploration revealed normal movements, reflexes, and sensitivity in all extremities. The patient had normal plantar and other deep tendon reflexes. Cerebellar function and muscle strength were not evaluated due to the patient's lack of cooperation. Upon inspection, palpation, auscultation, and percussion, the cardio-respiratory system had no abnormal findings. Abdominal examination yielded no alterations. Upon admission, the patient had the following vital signs: blood pressure of 120/60 mm Hg; a heart rate of $85 \mathrm{bpm}$; a respiratory rate of 17 $\mathrm{rpm}$; a body temperature of $36.5^{\circ} \mathrm{C}$; a body weight of $75 \mathrm{~kg}$; the height of $168 \mathrm{~cm}$; and BMI of 26.6.

\section{Clinical Evolution}

The patient was initially evaluated by the Psychiatry Department and was diagnosed with delirium due to unknown or unspecified etiological factors (International Statistical Classification of Diseases and Related Health Problems-11, 6D70.3). Management was initiated with olanzapine $20 \mathrm{mg}$ orally (per os, p.o.) every (quaque, q) $24 \mathrm{~h}$. After being evaluated by the Neurology Department, the presumptive diagnosis of unspecified encephalitis (ICD-11, 1D00.Z) was integrated. Laboratory results on admission are presented in Table 1. A computed tomography (CT) of the brain was performed to assess intra-axial lesions (e.g., hemorrhage, ischemia, and tumors) with normal findings. The CSF analysis reported a cloudy aspect with pleocytosis (i.e., 200 cells per $\mathrm{mm}^{3}$ ), normal protein (i.e., $30.8 \mathrm{mg} / \mathrm{dL}$ ) and glucose (i.e., $59 \mathrm{mg} / \mathrm{dL}$ ) levels (Table 1). Treatment with acyclovir $800 \mathrm{mg}$ intravenous (i.v.) q8h, as well as ceftriaxone $1 \mathrm{~g}$ i.v. $\mathrm{q} 12 \mathrm{~h}$ and vancomycin $1 \mathrm{~g}$ i.v. $\mathrm{q} 12 \mathrm{~h}$ for 10 days was initiated due to the possibility of an infection of the central nervous system. To exclude systemic viral infection or drug use, the following tests were requested: antibodies for hepatitis B virus, hepatitis $C$ virus, and HIV, as well as urinalysis for benzodiazepines, barbiturates, cannabis, cocaine, methamphetamines, and opiates; all results were reported as negative (Table 2, Table 3). Blood, bronchial secretion, and urine cultures were performed; with all cultures reporting negative results. Procalcitonin serum level was $0.4 \mathrm{ng} / \mathrm{mL}$. A meningoencephalitis PCR assay was performed with no reported bacteria, viral, or yeast infection (Table 2, Table 3) and the culture of the CSF was reported negative. After an infectious etiology was excluded, antiviral and antibiotic therapy were suspended. An electroencephalogram (EEG) was also performed yielding no epileptogenic or abnormal activity.

After 5 days of hospitalization, the patient started to develop asterixis and hyperreflexia in the lower extremities, followed by one generalized tonic-clonic seizure with loss of consciousness. A second EEG was performed after the ictal episode without evidence of epileptogenic or abnormal activity. Management with phenytoin $1 \mathrm{~g}$ i.v. was given as an initial dose, followed by $200 \mathrm{mg}$ p.o. q8h, as well as magnesium valproate $600 \mathrm{mg}$ p.o. q12h. Alprazolam $15 \mathrm{mg}$ p.o. q12h was administered to control the psychomotor agitation. The patient developed a urinary tract infection (Table 2, Table 3 ) but no microorganism was isolated from urine culture; thus ceftriaxone $1 \mathrm{~g}$ i.v. $\mathrm{q} 12 \mathrm{~h}$ for 7 days was administered. The patient developed hypertension (i.e., on average $160 / 100 \mathrm{~mm} \mathrm{Hg}$ on several occasions) which was treated with metoprolol $100 \mathrm{mg}$ p.o. q12h and amlodipine $5 \mathrm{mg}$ p.o. q12h with adequate control. The patient continued with lower extremity hyperreflexia, asterixis, nuchal rigidity, and aggressiveness. In search of an autoimmune etiology, the following serum tests were requested: cytoplasmic antineutrophil cytoplasmatic antibodies, perinuclear antineutrophil cytoplasmatic antibodies, anti-double-stranded deoxyribonucleic acid, anti-cardiolipin IgG, anti-cardiolipin 


\section{Case Reports in Neurology}

Case Rep Neurol 2019;11:330-343

DOI: $10.1159 / 000504016$

2019 The Author(s). Published by S. Karger AG, Basel www.karger.com/crn

Jiménez-Zarazúa et al.: Headache, Delirium or Encephalitis

IgM antibody and anti-NMDAR IgG antibody; all were reported as negative, except antiNDMAR IgG (Table 2, Table 3). Following a positive serum anti-NMDAR, these results were corroborated in CSF. Methylprednisolone $1 \mathrm{~g}$ i.v. was administered q24h for 5 days, followed by prednisone $70 \mathrm{mg}$ p.o. q24h and azathioprine $100 \mathrm{mg}$ p.o. q24h. Therapeutic plasmapheresis was administered $\mathrm{q} 72 \mathrm{~h}$ for a total of 5 sessions; showing notable improvement (i.e., no hyperreflexia, asterixis, nuchal rigidity, and aggressiveness; but continued mutism) after the last session.

The following tumor markers were screened, and all were reported negative: $\alpha$-fetoprotein, human chorionic gonadotropin, CA125, CA153, CA19.9, and carcinoembryonic antigen (Table 2, Table 3). Screening for a neoplastic process in the brain, simple and contrasted MRI (Fig. 1a-c) were performed, while simple and contrasted thoracic, abdominal, and pelvic CTs were also performed (Fig. 1d-f) to noninvasively assess tumor presence or apparent lymphadenopathy; all imaging modalities reporting normal results. To further search for a primary tumor site, a positron emission tomography was scheduled but the patient refused to undergo this procedure due to clinical improvement and invasiveness nature of the procedure. Regarding the association between germ cell tumors and paraneoplastic encephalitis, testicular ultrasonography was performed with no abnormal findings (Fig. 2a, b). The patient was diagnosed as having paraneoplastic or autoimmune encephalitis (ICD-11, 8E4A.0); furthermore, a stepwise diagnostic and treatment management procedure is depicted in Figure 3. After a month of hospitalization, the patient was released due to clinical improvement. Two months after his discharge, the patient was assessed at the outpatient neurology clinic. The patient remained without movement disorders, memory deficits or neuropsychiatric symptoms. Prednisone $50 \mathrm{mg}$ p.o. q24h, azathioprine $50 \mathrm{mg}$ p.o. $\mathrm{q} 12 \mathrm{~h}$, and magnesium valproate $500 \mathrm{mg}$ p.o. q12h were established as the maintenance therapy. Since the patient's language dysfunction persisted, he was referred to the Occupational Therapy and Psychiatry Departments to assist his needs.

\section{Discussion}

The case presented here is an example of a stepwise diagnostic and therapeutic approach for patients who develop neuropsychiatric symptoms associated with unspecified encephalitis. This case can assist neurologists, psychiatrists, as well as internal medicine and general practitioners to expediently recognize, diagnose and treat autoimmune encephalitis at a primary and secondary level of contact. Adequate and prompt recognition of the symptoms and clinical evolution is necessary for autoimmune encephalitis to improve the patient's prognosis. The clinician must bear in mind that anti-NMDAR encephalitis has been reported to represent approximately $1 \%$ of all the intensive care unit admissions of young patients [9]. Furthermore, after infectious diseases and acute disseminated encephalomyelitis, anti-NMDAR encephalitis is the third leading cause of encephalitis $[10,15]$. More than 600 cases around the world had been reported since the first cases were identified in 2005 [14]; however, most of these cases are from retrospective case studies. Considering that most of these reports have been reported employing a retrospective analysis of CFS samples, there is a need for prospective studies relating the diagnostic algorithm needed to ensure that the adequate treatment is provided on a timely fashion. This case report attempts to provide a concise diagnostic 


\section{Case Reports in Neurology}

Case Rep Neurol 2019;11:330-343

DOI: $10.1159 / 000504016$

(C) 2019 The Author(s). Published by S. Karger AG, Basel www.karger.com/crn

Jiménez-Zarazúa et al.: Headache, Delirium or Encephalitis

approach (Fig. 3) for clinical settings that do not harbor large populations at risk of encephalitis or concentrate many of these cases.

The case presented above begins with a clinical picture resembling a tension headache (i.e., tension of face and neck muscles); however, as the neurological alterations progressed (i.e., visual and auditory hallucinations, anxiety, and aggressiveness), a diagnosis of delirium was integrated. In anti-NMDAR encephalitis headache often develops alongside fever and pleocytosis, but it is rapidly replaced by psychiatric symptoms [16]. While isolated psychiatric episodes are rare and can occur as initial onset or relapse of anti-NMDAR encephalitis [13], the patient's level of consciousness decreased, and memory deficits and language dysfunction ensued; consequently, encephalitis became the suspected diagnosis. Initially, infectious etiologies were screened, and metabolic and toxicological etiologies were explored. CSF analysis is the gold standard for neurologic infection diagnosis. CSF culture, pathogen-specific polymerase chain reaction, antigen, and antibody tests are among the diagnostic tools for neuroinvasive infections [4]. In 2016, leading experts in the field proposed a diagnostic algorithm based on a syndrome-based diagnostic approach. In this approach, the authors provide criteria for the clinical diagnosis of possible autoimmune encephalitis [3]. These criteria include: (1) subacute onset (i.e., less than 3 months) of memory deficits, altered mental status or psychiatric symptoms; (2) associated with new focal central nervous system findings, seizures, CSF pleocytosis or MRI findings suggestive of encephalitis; and (3) reasonable exclusion of alternative causes [3]. The case presented here on admission fulfilled the first two criteria (i.e., psychiatric symptoms and CSF pleocytosis). As infectious, metabolic and toxicological causes of encephalitis were assessed, the patient's clinical picture progressed. No alterations in the patient's neuroimaging and electrophysiological assessment were identified; however, extreme delta brush in EEG has been associated with anti-NMDAR encephalitis [17]. Furthermore, our patient did not display EEG alterations before or after the seizure episode.

While the patient's clinical picture did not improve with antibiotic or antiviral therapy, movement disorders, other psychiatric manifestations, as well as autonomic instability were established in the clinical picture. After infectious, metabolic, and toxicological etiologies were excluded, autoimmune and paraneoplastic causes were explored. Once the autoimmune etiology was identified in serum and corroborated in CSF, the patient was treated with systemic corticosteroid and plasmapheresis therapy with a positive outcome. Therapeutic plasmapheresis is considered a first-line therapy with a strong recommendation based on observational studies or case series (i.e., grade $1 \mathrm{C}$ recommendation) [18]. Our patient responded well to the systemic corticoid steroid and plasmapheresis therapy. After 3 months of continuous therapy, mutism was the only focal neurological deficit that persisted in our patient. In a large multicenter observational study involving anti-NMDAR encephalitis, over half (i.e., 53\%) of the patients responded favorably within 4 weeks to first-line therapy or tumor removal, while some patients took up to 18 months to recover [19].

\section{Limitations}

After anti-NDMAR encephalitis is identified, a neoplastic process must be excluded [3]. Teratomas have been primarily associated with anti-NMDAR encephalitis in 50\% of females between 12 and 45 years [20]. Other tumors associated with anti-NMDAR encephalitis are ovarian teratoma [14, 21], Hodgkin lymphoma [22], ovarian cystadenofibroma [23], and testicular germ-cell tumors [24]. One of the main limitations of this case report is that positron 
emission tomography imaging to rule out a tumor was not performed; however, simple and contrasted thoraco-abdominopelvic CT, simple and contrasted brain MRI, and testicular ultrasonography were performed in search of tumors. Another limitation of this study is that antibodies in search of other autoimmune etiologies (e.g., the AMPA receptor, the GABA(B) receptor, and the glycine receptor) were not assessed.

\section{Conclusion}

When prodromal headache associated with psychiatric symptoms, memory deficits, decreased levels of consciousness, dyskinesia, autonomic instability, and language dysfunction is present on a patient with a subacute onset, autoimmune encephalitis must be suspected. While an infectious, metabolic, toxicological cause must be assessed and excluded through CSF, serum and imaging modalities (e.g., MRI and CT), high suspicion of an autoimmune etiology must be suspected if the clinical picture progresses in spite of adequate antiviral and antibiotic treatment. Furthermore, appropriate first-line treatment with plasmapheresis and corticosteroid therapy must be initiated once infectious, metabolic or toxicological etiologies are excluded. Once the diagnosis of anti-NMDAR encephalitis is established, a clinical protocol in search of a neoplastic process must be initiated.

\section{Acknowledgments}

This study was supported by CONACyT (Consejo Nacional de Ciencia y Tecnología) grant \#440591. We would like to commend the work of the medical staff (i.e., specialists, medical residents, and nursing staff) of the Internal Medicine Department at Hospital General León.

\section{Statement of Ethics}

Approval from the ethics committee was not required due to the nature of this case report. Abiding by the Declaration of Helsinki, patient anonymity was guaranteed. Upon hospital admission, the patient signed an informed consent permitting the use of her clinical file information for didactic and research purposes.

\section{Disclosure Statement}

This research did not receive any specific grant from funding agencies in the commercial sector. The authors have no conflict of interest to disclose. 


\section{References}

1 Dubey D, Pittock SJ, Kelly CR, McKeon A, Lopez-Chiriboga AS, Lennon VA, et al. Autoimmune encephalitis epidemiology and a comparison to infectious encephalitis. Ann Neurol. 2018 Jan;83(1):166-77.

2 Venkatesan A, Tunkel AR, Bloch KC, Lauring AS, Sejvar J, Bitnun A, et al.; International Encephalitis Consortium. Case definitions, diagnostic algorithms, and priorities in encephalitis: consensus statement of the international encephalitis consortium. Clin Infect Dis. 2013 Oct;57(8):1114-28.

3 Graus F, Titulaer MJ, Balu R, Benseler S, Bien CG, Cellucci T, et al. A clinical approach to diagnosis of autoimmune encephalitis. Lancet Neurol. 2016 Apr;15(4):391-404.

4 Ramachandran PS, Wilson MR. Diagnostic Testing of Neurologic Infections. Neurol Clin. 2018 Nov;36(4):687-703.

5 Dalmau J, Graus F. Antibody-Mediated Encephalitis. N Engl J Med. 2018 Mar;378(9):840-51.

6 Esposito S, Principi N, Calabresi P, Rigante D. An evolving redefinition of autoimmune encephalitis. Autoimmun Rev. 2019 Feb;18(2):155-63.

7 Ramanathan S, Mohammad SS, Brilot F, Dale RC. Autoimmune encephalitis: recent updates and emerging challenges. J Clin Neurosci. 2014 May;21(5):722-30.

8 Vitaliani R, Mason W, Ances B, Zwerdling T, Jiang Z, Dalmau J. Paraneoplastic encephalitis, psychiatric symptoms, and hypoventilation in ovarian teratoma. Ann Neurol. 2005 Oct;58(4):594-604.

9 Prüss H, Dalmau J, Harms L, Höltje M, Ahnert-Hilger G, Borowski K, et al. Retrospective analysis of NMDA receptor antibodies in encephalitis of unknown origin. Neurology. 2010 Nov;75(19):1735-9.

10 Gable MS, Sheriff H, Dalmau J, Tilley DH, Glaser CA. The frequency of autoimmune N-methyl-D-aspartate receptor encephalitis surpasses that of individual viral etiologies in young individuals enrolled in the California Encephalitis Project. Clin Infect Dis. 2012 Apr;54(7):899-904.

11 Hara M, Martinez-Hernandez E, Ariño H, Armangué T, Spatola M, Petit-Pedrol M, et al. Clinical and pathogenic significance of IgG, IgA, and IgM antibodies against the NMDA receptor. Neurology. 2018 Apr;90(16):e1386-94.

12 Gresa-Arribas N, Titulaer MJ, Torrents A, Aguilar E, McCracken L, Leypoldt F, et al. Antibody titres at diagnosis and during follow-up of anti-NMDA receptor encephalitis: a retrospective study. Lancet Neurol. 2014 Feb;13(2):167-77.

13 Kayser MS, Titulaer MJ, Gresa-Arribas N, Dalmau J. Frequency and characteristics of isolated psychiatric episodes in anti-N-methyl-d-aspartate receptor encephalitis. JAMA Neurol. 2013 Sep;70(9):1133-9.

14 Viaccoz A, Desestret V, Ducray F, Picard G, Cavillon G, Rogemond V, et al. Clinical specificities of adult male patients with NMDA receptor antibodies encephalitis. Neurology. 2014 Feb;82(7):556-63.

15 Granerod J, Ambrose HE, Davies NW, Clewley JP, Walsh AL, Morgan D, et al.; UK Health Protection Agency (HPA) Aetiology of Encephalitis Study Group. Causes of encephalitis and differences in their clinical presentations in England: a multicentre, population-based prospective study. Lancet Infect Dis. 2010 Dec;10(12):835-44.

16 Tominaga N, Kanazawa N, Kaneko A, Kaneko J, Kitamura E, Nakagawa H, Iizuka T. Prodromal headache in anti-NMDAR encephalitis: An epiphenomenon of NMDAR autoimmunity. Brain Behav. 2018 Jul;8(7):e01012.

17 Schmitt SE, Pargeon K, Frechette ES, Hirsch LJ, Dalmau J, Friedman D. Extreme delta brush: a unique EEG pattern in adults with anti-NMDA receptor encephalitis. Neurology. 2012 Sep;79(11):1094-100.

18 Schwartz J, Padmanabhan A, Aqui N, Balogun RA, Connelly-Smith L, Delaney M, et al. Guidelines on the Use of Therapeutic Apheresis in Clinical Practice-Evidence-Based Approach from the Writing Committee of the American Society for Apheresis: The Seventh Special Issue. J Clin Apher. 2016 Jun;31(3):149-62.

19 Titulaer MJ, McCracken L, Gabilondo I, Armangué T, Glaser C, Iizuka T, et al. Treatment and prognostic factors for long-term outcome in patients with anti-NMDA receptor encephalitis: an observational cohort study. Lancet Neurol. 2013 Feb;12(2):157-65.

20 Grativvol RS, Cavalcante WC, Castro LH, Nitrini R, Simabukuro MM. Updates in the Diagnosis and Treatment of Paraneoplastic Neurologic Syndromes. Curr Oncol Rep. 2018 Nov;20(11):92.

21 Dalmau J, Gleichman AJ, Hughes EG, Rossi JE, Peng X, Lai M, et al. Anti-NMDA-receptor encephalitis: case series and analysis of the effects of antibodies. Lancet Neurol. 2008 Dec;7(12):1091-8.

22 Zandi MS, Irani SR, Follows G, Moody AM, Molyneux P, Vincent A. Limbic encephalitis associated with antibodies to the NMDA receptor in Hodgkin lymphoma. Neurology. 2009 Dec;73(23):2039-40.

23 Sanmaneechai O, Song JL, Nevadunsky N, Moshé SL, Overby PJ. Anti-N-methyl-d-aspartate encephalitis with ovarian cystadenofibroma. Pediatr Neurol. 2013 Mar;48(3):232-5.

24 Lancaster E, Martinez-Hernandez E, Dalmau J. Encephalitis and antibodies to synaptic and neuronal cell surface proteins. Neurology. 2011 Jul;77(2):179-89. 


\section{Case Reports in Neurology}

Case Rep Neurol 2019;11:330-343
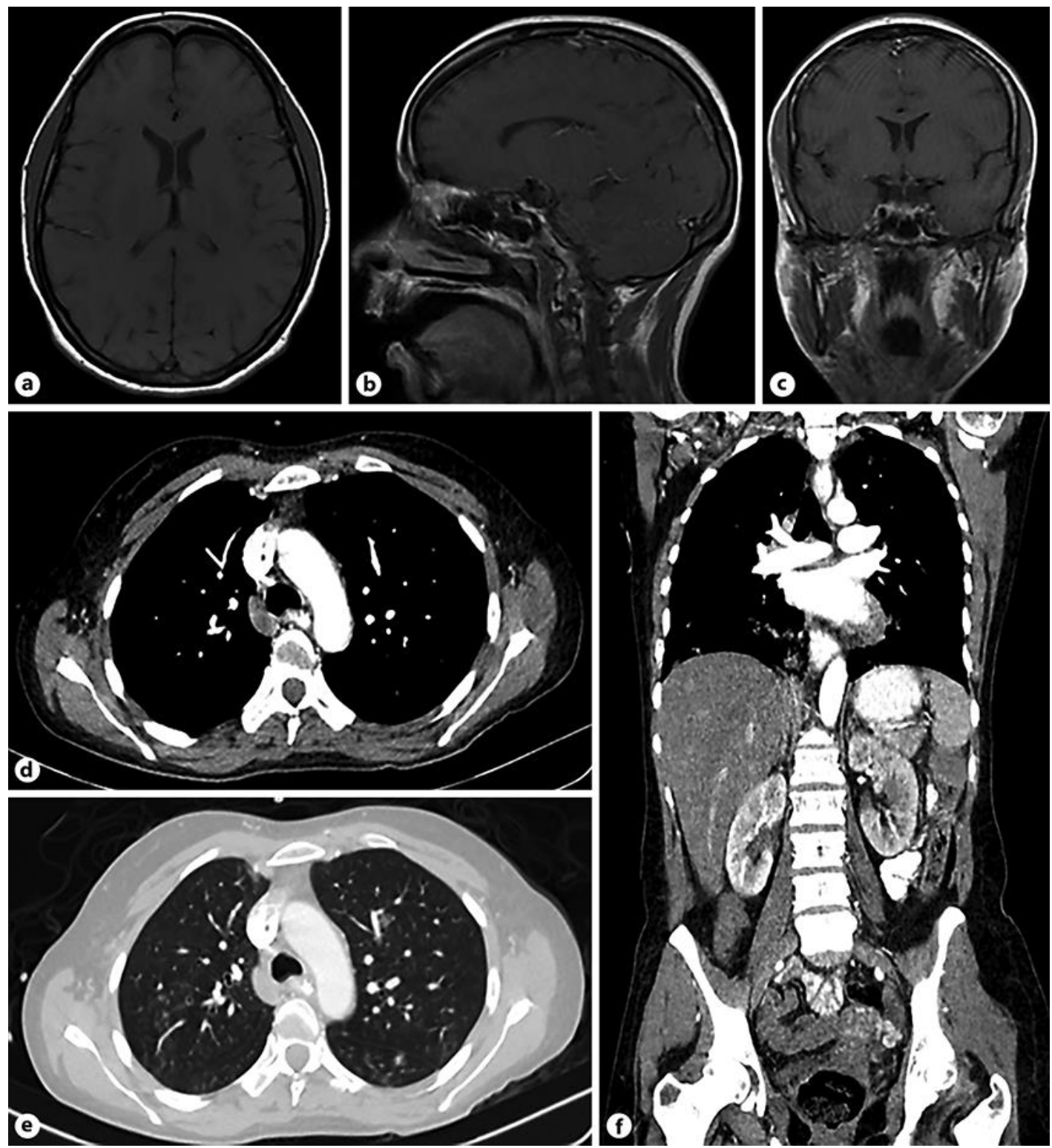

Fig. 1. Brain and thoraco-abdominopelvic imaging. Brain magnetic resonance imaging (MRI) and thoracoabdominopelvic computed tomography (CT). Normal (a) axial, sagittal (b), and coronal (c) T1-weighted brain MRI scans. $\mathbf{d}$ Normal CT of the thorax with contrast and mediastinal window. e Normal CT of the thorax with contrast and pulmonary window. $f$ Normal coronal reconstruction of thoraco-abdominopelvic CT with contrast. 


\section{Case Reports in Neurology}
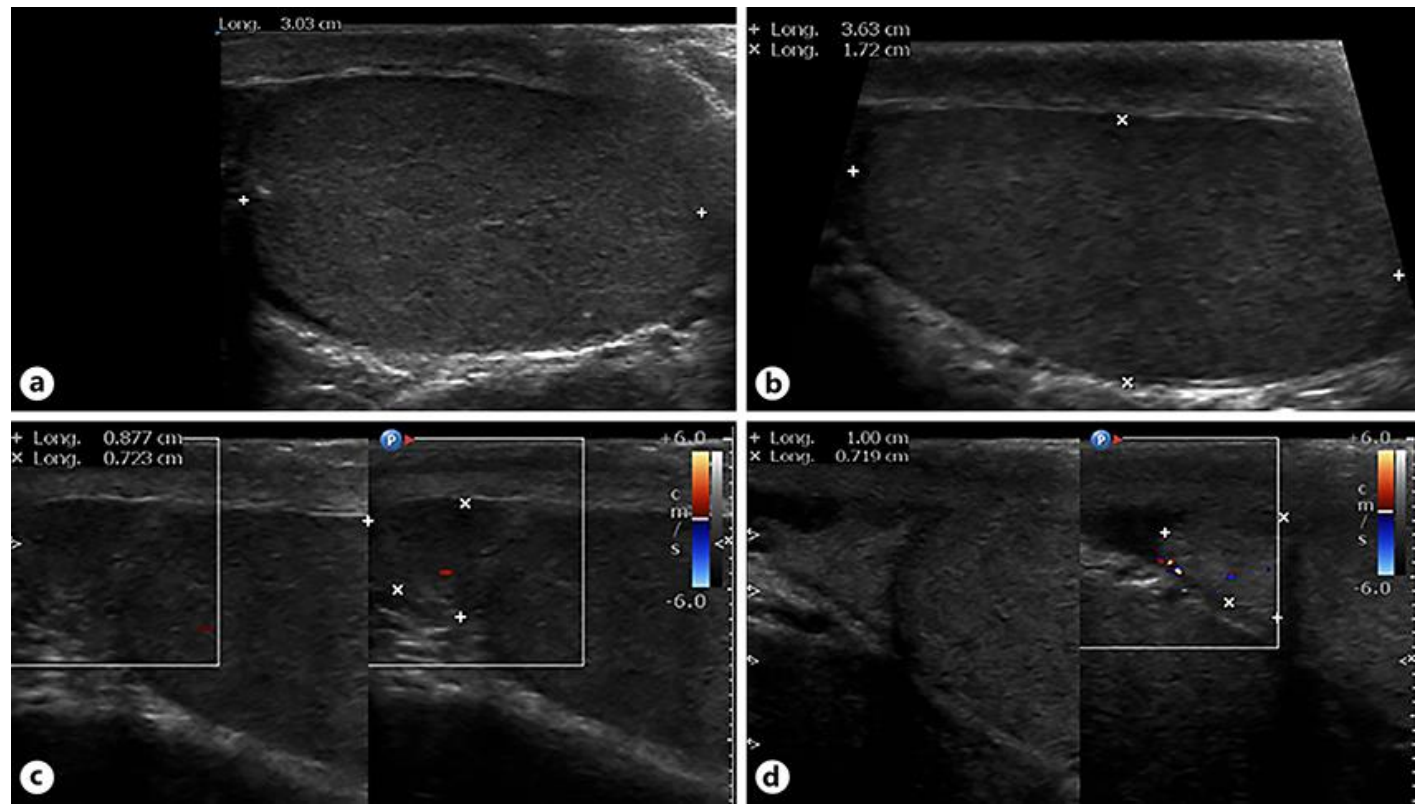

Fig. 2. Testicular ultrasonography. Testicular ultrasonography. a Longitudinal view of the right testicle with preserved echogenicity and with no pathological findings. b Longitudinal view of the left testicle with preserved echogenicity and with no pathological findings. c Longitudinal view of the right epididymis with preserved echogenicity and no pathological findings in gray-scale and Doppler ultrasonography. $\mathbf{d}$ Longitudinal view of the left epididymis with preserved echogenicity and no pathological findings in gray-scale and Doppler ultrasonography. 


\section{Case Reports in Neurology}

Case Rep Neurol 2019;11:330-343

DOI: $10.1159 / 000504016$

(c)

(C) 2019 The Author(s). Published by S. Karger AG, Basel www.karger.com/crn

Jiménez-Zarazúa et al.: Headache, Delirium or Encephalitis

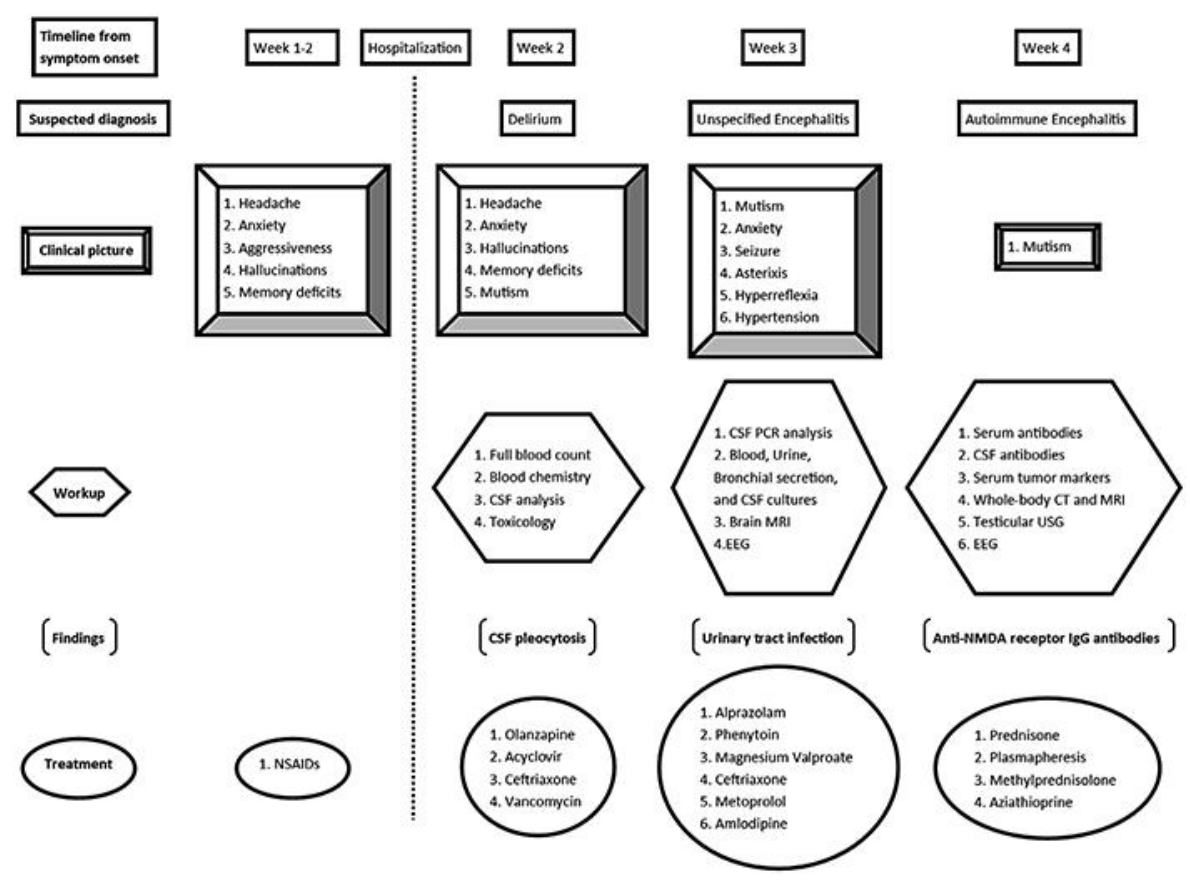

Fig. 3. Multi-step diagnostic and treatment management procedure. NSAIDs, nonsteroidal anti-inflammatory drugs. CSF, Cerebrospinal fluid. PCR, polymerase chain reaction. MRI, magnetic resonance imaging. EEG, electroencephalography. CT, computer tomography. USG, ultrasonography. NDMA, N-methyl-D-aspartate. IgG, Immunoglobulin G. 
Table 1. Laboratory test results upon admission

\begin{tabular}{|c|c|c|c|}
\hline \multirow{2}{*}{$\begin{array}{l}\text { Full blood count } \\
\text { Hemoglobin }\end{array}$} & \multicolumn{2}{|r|}{ Thyroid function tests } & \multirow[b]{2}{*}{$8.49 \mu \mathrm{g} / \mathrm{dL}$} \\
\hline & $14 \mathrm{~g} / \mathrm{dL}$ & Serum thyroxine (T4) & \\
\hline Hematocrit & $46 \%$ & Free thyroxine (FT4F) & $1.08 \mathrm{ng} / \mathrm{dL}$ \\
\hline Erythrocyte count & $5,100 \mu \mathrm{L}$ & Serum triiodothyronine (T3) & $88 \mathrm{ng} / \mathrm{dL}$ \\
\hline Platelet count & $300,000 \mu \mathrm{L}$ & T3 resin uptake (T3RU) & $2.55 \mathrm{pg} / \mathrm{mL}$ \\
\hline Mean corpuscular volume & $90.9 \mathrm{fL}$ & Serum thyrotropin (TSH) & $1.23 \mu \mathrm{U} / \mathrm{mL}$ \\
\hline Mean corpuscular hemoglobin concentration & $29.8 \mathrm{~g} / \mathrm{dL}$ & Blood coagulation & \\
\hline Leukocyte count & $8,500 \mu \mathrm{L}$ & Prothrombin time & $15 \mathrm{~s}$ \\
\hline Lymphocytes & $18.1 \%$ & Partial thromboplastin time & $35 \mathrm{~s}$ \\
\hline Neutrophils & $75.5 \%$ & International normalized ratio & 1.2 \\
\hline Monocytes & $5.9 \%$ & Electrolytes & \\
\hline Eosinophils & $0.2 \%$ & Sodium & $137 \mathrm{mEq} / \mathrm{dL}$ \\
\hline Basophils & $0.3 \%$ & Potassium & $4.1 \mathrm{mE} / \mathrm{dL}$ \\
\hline Blood chemistry & & Chlorine & $104.1 \mathrm{mEq} / \mathrm{dL}$ \\
\hline Glucose & $100 \mathrm{mg} / \mathrm{dL}$ & Calcium & $9.08 \mathrm{mg} / \mathrm{dL}$ \\
\hline Albumin & $3.5 \mathrm{~g} / \mathrm{dL}$ & Phosphorus & $3.5 \mathrm{mg} / \mathrm{dL}$ \\
\hline Urea nitrogen & $21.03 \mathrm{mg} / \mathrm{dL}$ & Magnesium & $2.1 \mathrm{mEq} / \mathrm{dL}$ \\
\hline Blood urea nitrogen & $45 \mathrm{mg} / \mathrm{dL}$ & Cerebrospinal fluid & \\
\hline Uric acid & $7 \mathrm{mg} / \mathrm{dL}$ & Aspect & Cloudy \\
\hline Cholesterol & $130 \mathrm{mg} / \mathrm{dL}$ & Leucocytes & 200 per $\mathrm{mm}^{3}$ \\
\hline Triglycerides & $110 \mathrm{mg} / \mathrm{dL}$ & Erythrocytes & None observed \\
\hline Liver function enzymes & & Protein & $30.8 \mathrm{mg} / \mathrm{dL}$ \\
\hline Aspartate transaminase & $35 \mathrm{U} / \mathrm{L}$ & Glucose & $59 \mathrm{mg} / \mathrm{dL}$ \\
\hline Alanine transaminase & $30 \mathrm{U} / \mathrm{L}$ & Cryptococcal antigen & Negative \\
\hline Lactate dehydrogenase & $240 \mathrm{U} / \mathrm{L}$ & Gram staining & No bacteria \\
\hline Albumin & $3.5 \mathrm{mg} / \mathrm{dL}$ & Culture & No development \\
\hline Alkaline phosphatase & $60 \mathrm{U} / \mathrm{L}$ & & \\
\hline Gamma-glutamyl transpeptidase & $30 \mathrm{U} / \mathrm{L}$ & & \\
\hline
\end{tabular}


Table 2. Follow-up laboratory test results: cerebrospinal fluid PCR assay

\section{Bacteria}

Escherichia coli $\mathrm{K} 1$

Not detected

Haemophilus influenzae

Not detected

Listeria monocytogenes

Not detected

Neisseria meningitides

Not detected

Streptococcus agalactiae

Not detected

Streptococcus pneumoniae

Not detected

Mycobacterium tuberculosis

No detected

\section{Viruses}

Cytomegalovirus

Not detected

Enterovirus

Herpes simplex virus 1

Herpes simplex virus 2

Human herpesvirus 6

Human parechovirus

Not detected

Not detected

Not detected

Varicella zoster virus

Not detected

Not detected

Not detected

\section{Yeast}

Cryptococcus neoformans/gattii

Not detected 
Table 3. Follow-up laboratory test results: cerebrospinal fluid PCR assay (continued)

\section{Serum antibodies}

Cytoplasmic antineutrophil cytoplasmatic antibodies (cANCA)

0.1

Perinuclear antineutrophil cytoplasmatic antibodies (pANCA)

0.2

Anti-double-stranded deoxyribonucleic acid

Anti-cardiolipin IgG antibody

Anti-cardiolipin IgM antibody

Anti-N-methyl-D-aspartate (NMDA) receptor IgG antibody

\section{Serum viral panel}

Hepatitis B virus

$0.6 \mathrm{IU} / \mathrm{mL}$

$3 \mathrm{IU} / \mathrm{mL}$

$3.1 \mathrm{IU} / \mathrm{mL}$

Positive

Hepatitis $C$ virus

Negative

Human immunodeficiency virus

Negative

Negative

\section{Serum tumor markers}

Alpha-fetoprotein

Human chorionic gonadotropin

CA125

CA153

$4.04 \mathrm{IU} / \mathrm{mL}$

$0.86 \mathrm{mU} / \mathrm{mL}$

$30 \mathrm{IU} / \mathrm{mL}$

$3 \mathrm{IU} / \mathrm{mL}$

CA19.9

$7.4 \mathrm{IU} / \mathrm{mL}$

Carcinoembryonic antigen

$0.83 \mathrm{ng} / \mathrm{mL}$

\section{Urinalysis}

Appearance

$\mathrm{pH}$

Cloudy

Specific gravity

6.0

Proteins

Ketones, glucose, and nitrite

1.032

$30 \mathrm{mg} / \mathrm{dL}$

Leukocytes

Erythrocytes

Bacteria

Negative

3 per high-power field

Bacteria

4 per high-power field

Benzodiazepines

Abundant

Barbiturates

Negative

Cannabis

Negative

Cocaine

Negative

Methamphetamines

Negative

Opiates

Negative

Negative 